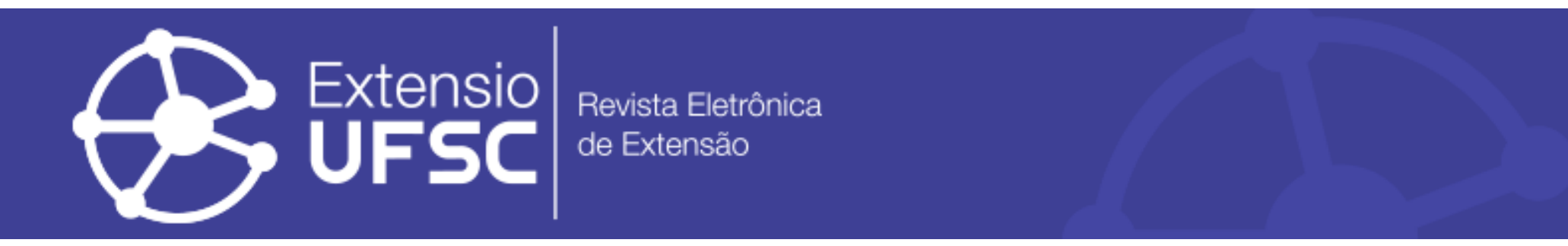

\title{
UM SISTEMA DE IDENTIDADE VISUAL PARA A IDENTIFICAÇÃO E DIFERENCIAÇÃO DE PRODUTOS DA AGRICULTURA FAMILIAR
}

Giselle Schmidt Alves Díaz Merino

Universidade Federal de Santa Catarina gisellemerino@gmail.com

Adriana Toutonje Mitozo

Universidade Federal de Santa Catarina adrianamitozo@gmail.com

Adriana Tomazi Alves

Universidade Federal de Santa Catarina adritomazi@epagri.sc.gov.br
Dione Nery Cavalcanti Benevenutti Universidade Federal Rural de Pernambuco dionenery@epagri.sc.gov.br

Henrique Tirolli Rett Universidade Estadual de Londrina henriquerett@epagri.sc.gov.br

Eugenio Andrés Díaz Merino Universidade Federal de Santa Catarina merino@cce.ufsc.br

\section{Resumo}

A agricultura familiar é responsável pela maior parte da produção de alimentos em Santa Catarina e no Brasil. Em Joinville/SC a Associação Joinvillense de Agroindústrias Artesanais Rurais (AJAAR), um empreendimento composto por 49 associados, produz alimentos caseiros em diversos segmentos. Esta ação de extensão enfocou no segmento de panificados, no qual foram identificadas fragilidades, como a falta de identificação dos produtores, produtos de excelente qualidade em embalagens inadequadas e falta de padronização na aplicação da marca. Visando identificar, valorizar e diferenciar os produtos da AJAAR, esta ação desenvolveu um Sistema de Identidade Visual (SIV) e suas aplicações, incluindo as embalagens dos panificados. Para o desenvolvimento da ação utilizou-se o Guia de Orientação para Desenvolvimento de Projetos, resultando em refinamentos na marca, desenvolvimento de embalagens e demais aplicações, que já vem sendo implementados pela associação, permitindo concluir que atividades desta natureza são essenciais para oportunizar uma efetiva aproximação entre academia e sociedade.

Palavras-chave: Design. Sistema de Identidade Visual. Agricultura Familiar.

\section{A VISUAL IDENTITY SYSTEM FOR IDENTIFICATION AND DIFFERENTIATION OF FAMILY FARMING PRODUCTS}

\begin{abstract}
Family farming is responsible for most of the food production in Santa Catarina and in Brazil. In Joinville/SC the Association of Rural Artisan Agro industries of Joinville (AJAAR), a company composed by 49 associated produces homemade food in various segments. This extension action focused on the bakery segment, in which weaknesses were identified, such as the lack of visual identification of the producers, excellent quality products in inadequate packaging and the lack of standardization in the brand applications. Aiming to identify, value and differentiate the products of AJAAR, this action developed a Visual Identity System and applications, including the baked goods packaging. For the development of this action, the Orientation Guide to Project Development was used, resulting in the brand refinements, packaging and other applications which have already been implemented by the association, allowing to conclude that activities of this nature are essential to provide an effective connection between academy and society.
\end{abstract}

Keywords: Design. Visual Identity System. Family Farming.

\section{UN SISTEMA DE IDENTIDAD VISUAL PARA LA IDENTIFICACIÓN Y DIFERENCIACIÓN DE PRODUCTOS DE LA AGRICULTURA FAMILIAR}

\begin{abstract}
Resumen
La agricultura familiar es responsable de la mayor parte de la producción de alimentos en Santa Catarina y Brasil. En Joinville / SC la Asociación Joinvillense de Agroindustrias Artesanales Rurales (AJAAR), es un emprendimiento formado por 49 asociados, produce alimentos caseros en diversos segmentos. Esta acción de extensión se enfocó en el segmento de panificados, en el cual se identificaron fragilidades, como la falta de identificación de los productores, productos de excelente calidad en envases inadecuados y falta de estandarización en la aplicación de la marca. Con la finalidad de identificar, valorizar y diferenciar los productos de AJAAR, esta acción desarrolló un Sistema de Identidad Visual (SIV) y sus aplicaciones, incluyendo los embalajes de los panificados. Para el desarrollo de la acción se utilizó la Guía de Orientación para el Desarrollo de Proyectos, resultando en refinamientos en la marca, desarrollo de envases y demás aplicaciones, que ya vienen siendo implementados por la asociación, permitiendo concluir que actividades de esta naturaleza son esenciales para crear oportunidades de una efectiva aproximación entre la academia y la sociedad.

Palavras clave: Diseño. Sistema de Identidad Visual. Agricultura Familiar.
\end{abstract}


Um Sistema de Identidade Visual para a identificação e diferenciação de produtos da agricultura familiar

\section{INTRODUÇÃO}

Agricultura familiar é a prática de atividades no meio rural realizada por pequenos proprietários rurais, na qual a gestão de propriedade e a mão de obra é compartilhada pela família e a atividade agropecuária é a principal fonte de renda. Além disso, por ser seu local de trabalho e moradia, o agricultor familiar tem uma relação especial com a terra (MINISTÉRIO DO DESENVOLVIMENTO AGRÁRIO, 2016). Neste contexto, os agricultores familiares podem se organizar por meio de empreendimentos coletivos, que reúnem pessoas com objetivos comuns, tendo em vista superar dificuldades e gerar benefícios para seus integrantes, de forma a criar um diferencial competitivo para pequenos negócios, contribuindo assim para seu crescimento (SEBRAE, 2014).

Santa Catarina é um dos estados com maior percentual de agricultores familiares do país (MATTEI, 2010). Segundo dados do último Censo Agropecuário, realizado em 2006, mais de 168 mil estabelecimentos agropecuários do estado foram classificados como sendo parte da Agricultura Familiar, atingindo 87\% do total (IBGE, 2006).

Uma pesquisa realizada pela Empresa de Pesquisa Agropecuária e Extensão Rural de Santa Catarina (EPAGRI) sobre as perspectivas para o sistema agroalimentar e o espaço rural do estado em 2015 mostrou que, entre as estratégias comerciais da produção regional no futuro, estão a agregação de valor, diferenciação do produto, desenvolvimento em design e embalagem, melhoria da qualidade e fidelização de clientes (ALTMANN, MIOR, ZOLDAN, 2008).

Apesar de sua relevância no âmbito estadual, no contexto do design observam-se algumas dificuldades e fragilidades enfrentadas por este setor. Entre elas, encontram-se a falta de identificação visual dos produtos e de seus produtores; a presença de produtos de boa qualidade em embalagens inadequadas, irregularidades no registro legal, dificuldades de inserção no mercado, limitada ou inexistente diferenciação dos produtos, entre outros (MERINO et al., 2016). Desta forma, o design pode contribuir para a identificação e diferenciação, por meio do desenvolvimento de um sistema de identidade visual ${ }^{1}$ e para a proteção de seus produtos - desde a fabricação até a chegada ao consumidor final -, por meio de embalagens adequadas. Além disso, uma embalagem apropriada funciona como uma interface direta entre empresa e

\footnotetext{
1 "O Sistema de Identidade Visual (...) é como se configura objetivamente a identidade. Formam o sistema todos os veículos que veiculem os elementos básicos da identidade visual: o logotipo o símbolo, a marca, as cores institucionais e o alfabeto institucional, além de outros eventuais elementos acessórios, que são aplicados em itens específicos (material de papelaria, letreiros, uniformes, sinalização, embalagens, gráfica, ambiente, etc.) Estes veículos são chamados de aplicações" (Peón, 2000. Pag 14)
} 
Um Sistema de Identidade Visual para a identificação e diferenciação de produtos da agricultura familiar

usuário/consumidor por meio da utilização de recursos visuais que auxiliam na tomada de decisão, além de auxiliar no transporte e proteção dos produtos (MERINO et al., 2016).

Segundo a Associação Brasileira de Embalagem (ABRE), a embalagem é um recipiente que armazena produtos individualmente ou agrupando unidades. E no caso de produtos alimentícios, existe a obrigatoriedade por lei do uso de rótulo que deve estar em conformidade (AGÊNCIA NACIONAL DE VIGILÂNCIA SANITÁRIA. Resolução RDC no 259, de 20 de setembro de 2002). Negrão e Camargo (2008) complementam que a embalagem possui as funções de acondicionar, proteger, ampliar a validade do produto, ser funcional, identificar, informar, formar e consolidar uma imagem, promover, vender e agregar valor.

Neste contexto, é importante aliar um bom design que evidencie e agregue valor a um produto de qualidade pois, segundo Mestriner (2002), mais de $90 \%$ dos produtos disponíveis em estabelecimentos de venda, não possuem apoio de propagandas e dependem unicamente da embalagem para conquistar a atenção do consumidor. Após chamar a atenção do consumidor, a embalagem precisa rapidamente oferecer informações sobre o produto, como por exemplo, o que ele é, para que serve e a quem se destina; além de atender as exigências legais em especial quanto aos componentes que podem provocar danos à saúde.

O consumidor considera a embalagem como parte integrante e inerente de um produto, constituindo para ele uma única peça. Sendo assim, a relevância do design de embalagem está no fato de ele incorporar o valor de cada uma das etapas do processo, pois traz como resultado uma embalagem que enaltece o trabalho de todos os envolvidos no desenvolvimento daquele produto, o que possibilita valorizar e identificar tanto o produto-produtor, no caso da agricultura familiar (MESTRINER, 2002).

Esta ação foi desenvolvida por meio do projeto de extensão registrado no Sistema Integrado de Gerenciamento de Projetos de Pesquisa e de Extensão (SIGPEX-UFSC) sob número 201710890, intitulado “Ações de valorização e identificação de empreendimentos rurais e pesqueiros nas regiões de Joinville, Blumenau e Grande Florianópolis". Esta iniciativa foi viabilizada em parceria com a EPAGRI, apoio do Banco Mundial e do Governo do Estado de Santa Catarina por meio do Programa SC Rural. Foi executada pelo Núcleo de Gestão de Design (NGD) e o Laboratório de Design e Usabilidade (LDU) da Universidade Federal de Santa Catarina (UFSC), por meio da Fundação de Amparo à Pesquisa e Extensão Universitária (FAPEU), envolvendo também os Programas de Pós-Graduação em Design (PÓSDESIGN) e Engenharia de Produção (PPGEP) da UFSC, caracterizando uma ação multidisciplinar.

Este artigo teve como objetivo desenvolver um Sistema de Identidade Visual (SIV) para os produtos da AJAAR, incluindo as embalagens do segmento de panificação, de modo a evidenciar a 
Um Sistema de Identidade Visual para a identificação e diferenciação de produtos da agricultura familiar

contribuição do design na valorização e diferenciação de produtos da agricultura familiar por meio de uma ação de extensão.

\section{MATERIAIS E MÉTODOS}

Este artigo caracteriza-se como uma ação de extensão e classifica-se como aplicada segundo sua natureza, pois tem como objetivo gerar conhecimentos para aplicação prática e direcionada à solução de problemas específicos. Segundo a forma de abordagem do problema, é classificada como pesquisa qualitativa, pois interpreta os fenômenos e a atribuição de significados, não requerendo o uso de técnicas estatísticas. Quanto aos seus objetivos classifica-se como exploratória, pois visa proporcionar maior familiaridade com o problema, envolvendo levantamento bibliográfico e estudo de caso (GIL, 2002).

O processo foi dividido em dois momentos, o primeiro de cunho teórico, no qual foram levantadas, organizadas e analisadas informações referentes aos temas centrais e um segundo momento, prático/aplicado referente ao desenvolvimento do SIV e embalagens, no qual foi utilizado o Guia de Orientação para Desenvolvimento de Projetos (GODP) como referência (MERINO, 2016). Durante todo o processo foram realizadas visitas in loco, sejam para o levantamento preliminar, discussões e apresentações dos resultados, caracterizando um processo participativo, entre a equipe, a AJAAR e demais envolvidos.

A ação teve o envolvimento direto de seres humanos no seu desenvolvimento, por esse motivo, foi solicitada autorização a Comissão Nacional de Ética em Pesquisa (CONEP), por meio da Plataforma Brasil, foi então avaliada e deferida pelo Comitê de Ética em Pesquisas com Seres Humanos da Universidade Federal de Santa Catarina, sob o parecer de aprovação número 2.064.627.

Quanto ao GODP, encontra-se estruturado em três momentos principais (Inspiração, Ideação e Implementação), e dividido em oito etapas de projeto que englobam desde a definição do problema, levantamento de informações, processo criativo, até a validação do projeto (Merino, 2016), conforme ilustração 1. Tendo como base o projeto centrado no usuário, o GODP coloca o ser humano em primeiro lugar durante o desenvolvimento de um produto ou serviço, portanto, se apresenta bastante apropriado para este tipo de ação. 
Um Sistema de Identidade Visual para a identificação e diferenciação de produtos da agricultura familiar

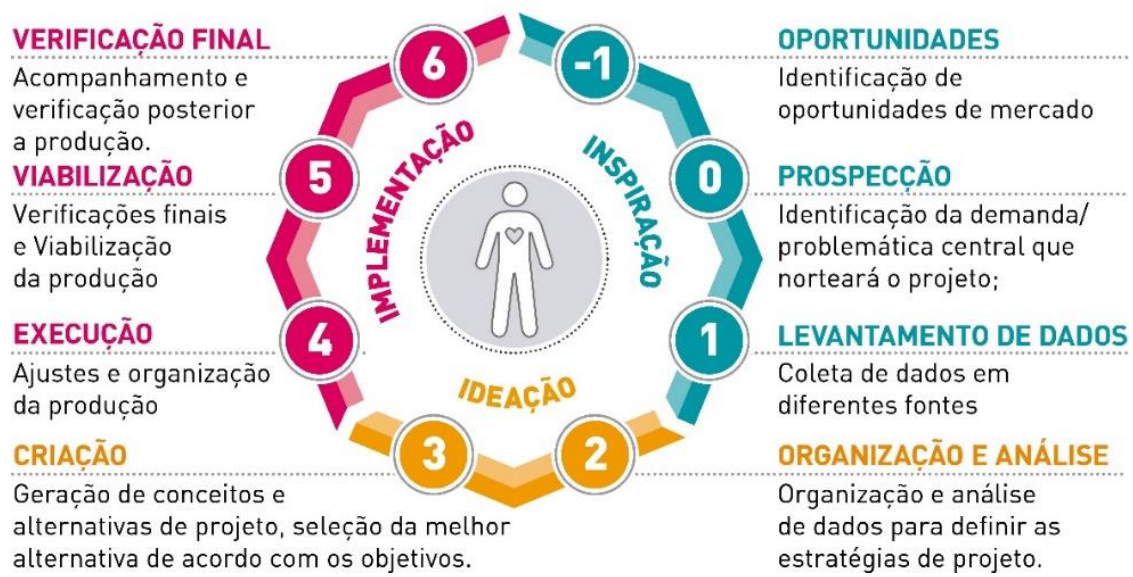

Ilustração 1 - Guia de Orientação para Desenvolvimento de Projetos Fonte: Merino, 2016.

Na etapa -1 (Oportunidades) identificam-se as oportunidades de mercado e setores de acordo com o produto que está sendo avaliado. Na Etapa 0 (Prospecção) é definida a demanda e a problemática central que conduzirá o projeto. $\mathrm{Na}$ Etapa 1 (Levantamento de Dados) é realizada uma coleta de dados conforme as necessidades do projeto. Na Etapa 2 (Organização e Análise) os dados da etapa anterior são organizados e analisados, de forma a permitir a delimitação das estratégias de projeto. Na Etapa 3 (Criação) os conceitos e requisitos de projeto são definidos, geradas as alternativas e escolhida a que atende de melhor forma os requisitos, habitualmente utiliza-se uma matriz de decisão. Na Etapa 4 (Execução) são desenvolvidos os protótipos com base na alternativa escolhida. Na Etapa 5 (Viabilização) são realizados estudos para a viabilização da produção. Na Etapa 6 (Verificação Final) é realizada uma verificação após o produto ser implementado. A seguir será apresentação a ação prática de extensão seguindo os momentos do GODP (inspiração, ideação e implementação).

\section{MOMENTO DE INSPIRAÇÃO E IDEAÇÃO}

A AJAAR é um empreendimento da Agricultura Familiar de Santa Catarina, fundada em 25 de setembro de 2000 e composta por 49 associados que produzem diversos produtos artesanais na cidade de Joinville. Entre estes produtos estão pães, bolos, biscoitos, aipim descascado congelado, geleias, mousses, queijos, raízes, entre outros.

O primeiro momento do GODP, denominado Inspiração, corresponde às etapas: Oportunidades (etapa -1), Prospecção (etapa 0) e Levantamento de Dados (etapa 1). Na ilustração 2 pode ser visualizado um resumo das ações realizadas no Momento Inspiração do GODP. 
Um Sistema de Identidade Visual para a identificação e diferenciação de produtos da agricultura familiar

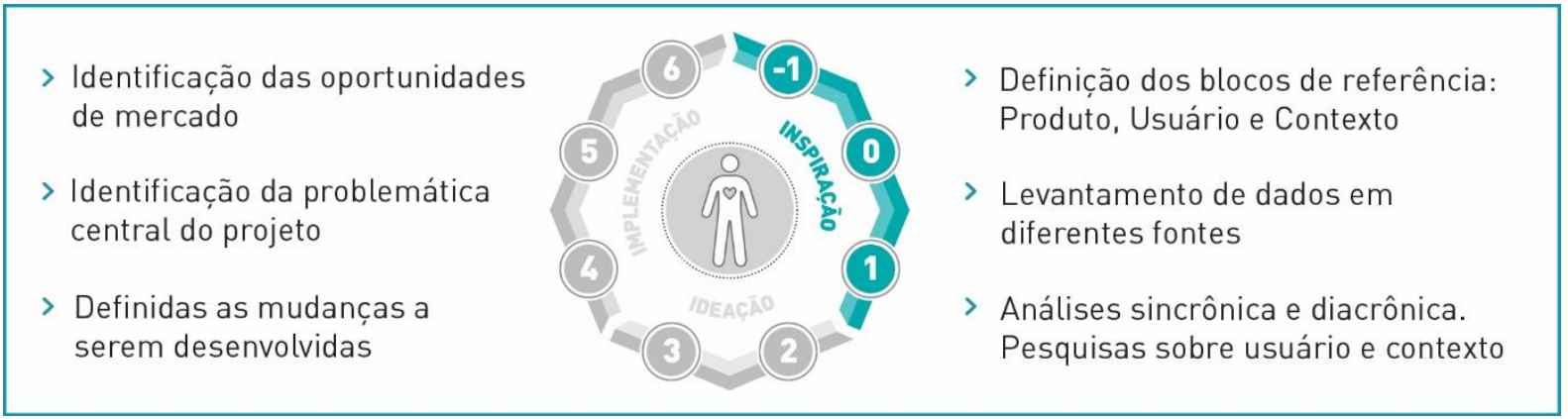

Ilustração 2 - Resumo do Momento Inspiração do GODP

Fonte: Os Autores, 2018.

Na etapa -1 foram verificadas as oportunidades de mercado, levando em consideração o cenário em que a marca está inserida, sendo assim reveladas as necessidades de mudanças e ajustes. Ao longo das pesquisas sobre a AJAAR verificou-se fragilidade nas embalagens de panificados (pães, bolos, cucas e biscoitos), tendo em vista que os produtos eram danificados durante o transporte e exposição e havia a necessidade de uma adequação dos rótulos a legislação, sendo necessária uma unificação e padronização da comunicação visual. $\mathrm{Na}$ embalagem de biscoito foi percebida uma maior necessidade de alteração, devido a sua fragilidade que fazia com que o produto quebrasse durante o transporte. Foi notado também que por se tratar de um empreendimento onde existem diversos produtores fabricando uma grande variedade de produtos, há a necessidade de se identificar nominalmente cada produtor nas embalagens.

$\mathrm{Na}$ etapa 0 foi realizado um estudo prévio que conduziu o projeto. Este estudo incluiu uma pesquisa no Instituto Nacional de Propriedade Industrial (INPI), no qual foi realizado uma busca para verificar a situação legal do registro da marca. Os resultados da pesquisa mostraram que a AJAAR já está com o registro de marca em vigor o que garante sua proteção. Nesta etapa também foram definidos os Blocos de Referência (Usuário, Produto e Contexto), fundamentais na prática projetual do designer que deve estar ciente da interação entre o produto que será criado, o usuário deste produto, e o contexto que ele será inserido. Para Merino (2016, p 8), sempre “(...) projetamos algo (produto), para alguém (usuário) em algum lugar (contexto)". Entende-se por Produto o resultado de um projeto. Neste caso, o Produto é o Sistema de Identidade Visual e suas aplicações, em especificamente as embalagens. O Usuário refere-se a quem irá se utilizar do produto. Neste caso, o Usuário são os produtores de panificados, assim como todos os envolvidos no processo de produção e venda do produto, e os consumidores finais. O Contexto diz respeito ao meio onde acontece a interação do produto com o usuário. Nesta ação, o contexto pode ser tanto no ponto de venda, como no ambiente em que o produto será consumido e acondicionado. 
Um Sistema de Identidade Visual para a identificação e diferenciação de produtos da agricultura familiar

$\mathrm{Na}$ etapa 1 o projeto foi definido e encaminhado com base em um levantamento de dados, compreendendo os dados dentro dos blocos de referência (Produto, Usuário e Contexto), que envolveu: pesquisas do histórico dos produtos oferecidos (diacrônica), análise de concorrentes e similares (sincrônica), análise morfológica dos produtos, análise dos consumidores e pesquisas sobre a localidade de Joinville onde o empreendimento está inserido. Nesta etapa foi possível identificar as necessidades do projeto, os problemas encontrados, conhecer os usuários e elaborar estratégias para que o produto se diferencie de seus concorrentes.

O segundo momento da metodologia GODP, denominado de Ideação, diz respeito às etapas Organização e Análise (etapa 2) e Criação (etapa 3). Um resumo das ações realizadas no Momento Ideação do GODP está representado na ilustração 3.

Organização dos dados coletados

Geração dos conceitos e requisitos de projeto

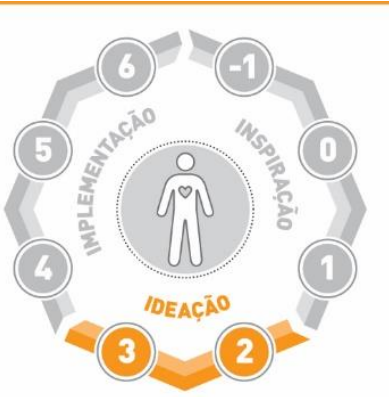

> Construção de painéis semânticos

$>$ Geração de alternativas

$>$ Ajustes na identidade visual

Ilustração 3 - Resumo do Momento Ideação do GODP Fonte: Os Autores, 2018.

$\mathrm{Na}$ etapa 2 os dados coletados na etapa anterior foram organizados em mapas e painéis, em seguida foram analisados. Foram gerados os Conceitos e os Requisitos de Projeto que nortearam o desenvolvimento do projeto, no caso desta ação, o Sistema de Identidade Visual, que inclui o redesign da marca, suas aplicações e as embalagens para os pães, bolos, cucas e biscoitos produzidos pela AJAAR.

Os conceitos gerados foram associados a cada um dos blocos de informação: artesanal (produto), saboroso (usuário) e seguro (contexto). Foram gerados também os requisitos de projeto relacionados aos conceitos, como pode ser visto na ilustração a seguir. 
Um Sistema de Identidade Visual para a identificação e diferenciação de produtos da agricultura familiar

\begin{tabular}{|c|c|c|}
\hline & CONCEITOS & REQUISITOS \\
\hline PRODUTO & $\begin{array}{l}\text { Artesanal } \\
\text { Feito em casa, } \\
\text { sem aditivos químicos, } \\
\text { produção local }\end{array}$ & $\begin{array}{l}\text { - Destacar nome do produtor nas embalagens; } \\
\text { - Destaque à produção artesanal } \\
\text { - Elementos que remetam ao produto feito } \\
\text { artesanalmente; }\end{array}$ \\
\hline USUÁR: & $\begin{array}{l}\text { Saboroso } \\
\text { De qualidade conhecida } \\
\text { pelos usuários, } \\
\text { ingredientes caseiros }\end{array}$ & $\begin{array}{l}\text { - Janela ou área transparente para visualizar o } \\
\text { produto }\end{array}$ \\
\hline CONTEXTO & $\begin{array}{l}\text { Seguro } \\
\text { Garantia, direto do } \\
\text { empreendimento, } \\
\text { resistente, confiável. }\end{array}$ & $\begin{array}{l}\text { - Embalagens resistentes. } \\
\text { - Possuir sistema de fechamento }\end{array}$ \\
\hline
\end{tabular}

Ilustração 4 - Conceitos e Requisitos de Projeto

Fonte: Os Autores, 2018.

A partir das informações da ilustração 4, foram elaborados painéis semânticos para cada conceito gerado (ilustração 5). Para Baxter (2000), painel semântico é uma espécie de quadro de referências visuais no que diz respeito a alguns elementos do projeto de design, como cores, texturas, formas e tipografia. Em cada painel foram observados padrões de cores, texturas, forma, composição e tipografia que estão associados aos conceitos que a nova embalagem deve transmitir.

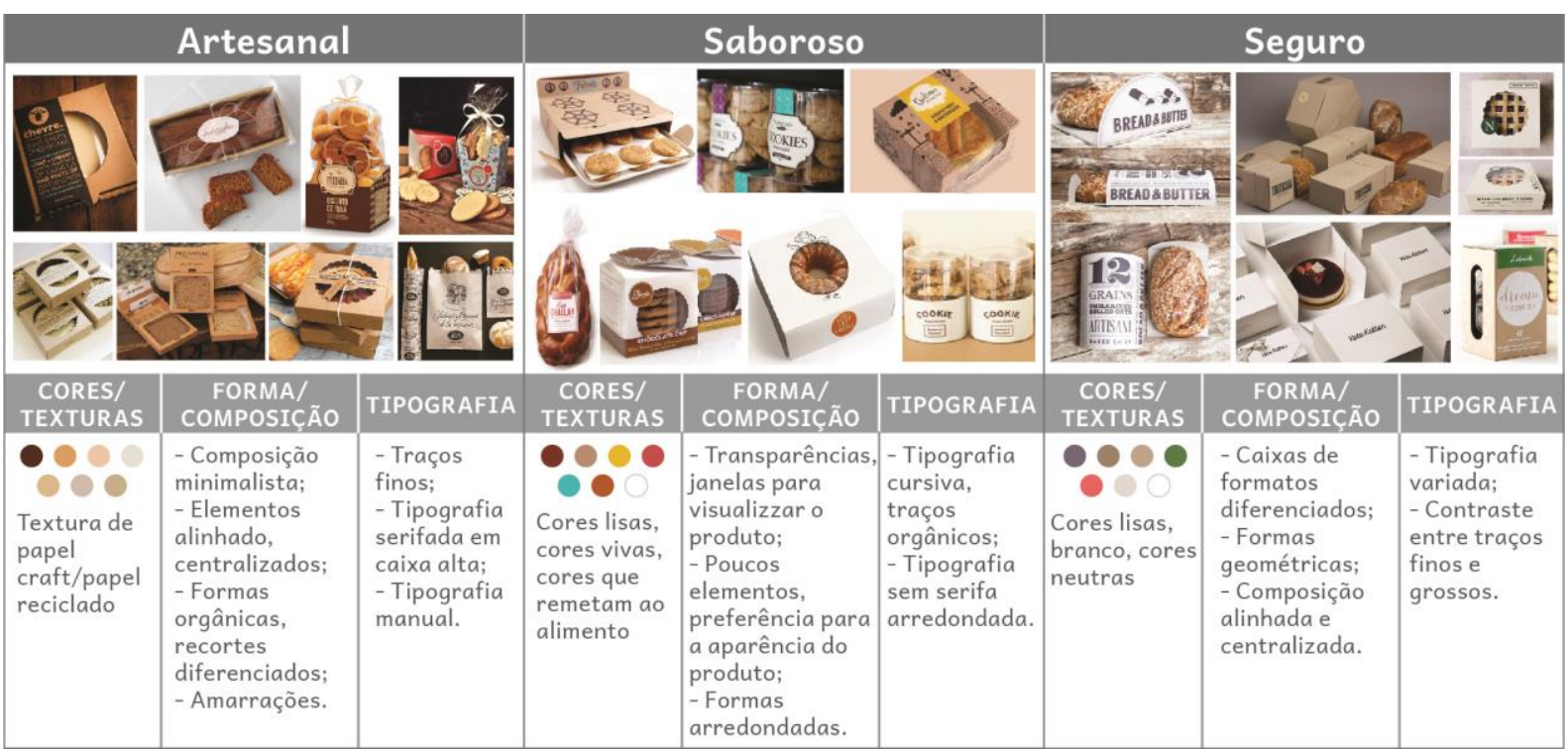

Ilustração 5 - Painéis Semânticos Fonte: Os Autores, 2018.

$\mathrm{Na}$ etapa 3 foram geradas as alternativas com base nos conceitos e requisitos de projeto. A AJAAR já possuía uma identidade visual, reconhecida entre seus consumidores. No entanto, observou-se que as embalagens traziam diferentes versões do logo. Verificou-se ainda que necessitava de ajustes nos elementos da marca e na tipografia, visto que apresenta problemas de legibilidade, principalmente nas reduções. Por este motivo, foi feito um ajuste na marca da identidade visual a fim de padronizar seu uso em todas as embalagens, como pode ser visualizado na ilustração 6 . 
Um Sistema de Identidade Visual para a identificação e diferenciação de produtos da agricultura familiar

A representação da casa no logo da AJAAR já está associada aos seus produtos e é conhecida por seus consumidores (representativa da cultura alemã). O logo vinha geralmente na frente do rótulo e estava desconectada do acrônimo $^{2}$ da AJAAR, comprometendo sua identificação.

$\mathrm{Na}$ nova proposta, foi utilizada uma única tipografia com o objetivo de criar uma unidade entre os dois logos. A sigla da AJAAR foi reposicionada junto do logo da casa e alguns elementos foram realinhados para proporcionar maior equilíbrio. No logo da AJAAR, a fonte do significado do seu acrônimo foi aumentada para facilitar a legibilidade quando houver redução.

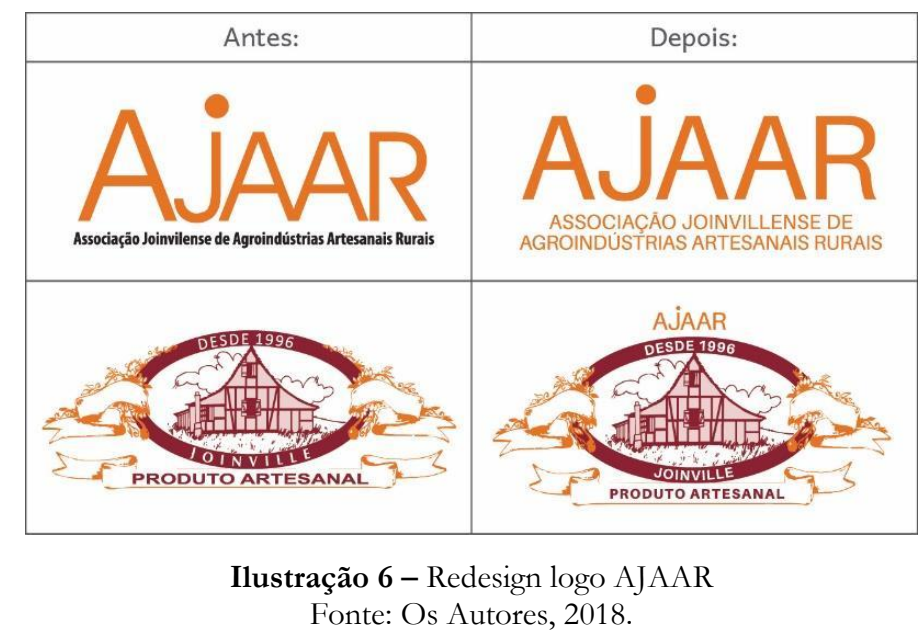

Conforme foi estabelecido nos requisitos de projeto, foram também criadas tags de identificação do produtor que serão anexadas às embalagens como forma de identificar e valorizar o produtor individualmente. Deste modo, os consumidores terão uma maior facilidade para visualizar o nome do produtor na embalagem; e o produtor, por sua vez, terá maior destaque e reconhecimento pelos seus produtos. Nesta etapa também foram desenvolvidos rótulos e embalagens para melhor acondicionar os panificados do empreendimento.

\section{MOMENTO DE IMPLEMENTAÇÃO}

O terceiro momento da metodologia GODP, Momento Implementação, corresponde às etapas Execução (etapa 4), Viabilização (Etapa 5) e Verificação Final (etapa 6). A etapa 6 não foi contemplada neste artigo, tendo em visto que está em processo de implementação. $\mathrm{Na}$ ilustração 7 pode ser visualizado um resumo das ações realizadas.

\footnotetext{
${ }^{2}$ Unidade formada por letras ou conjuntos de letras que se pronunciam como uma palavra, pois têm a estrutura silábica da língua onde se formam (CORREIA, 2005).
} 
Um Sistema de Identidade Visual para a identificação e diferenciação de produtos da agricultura familiar

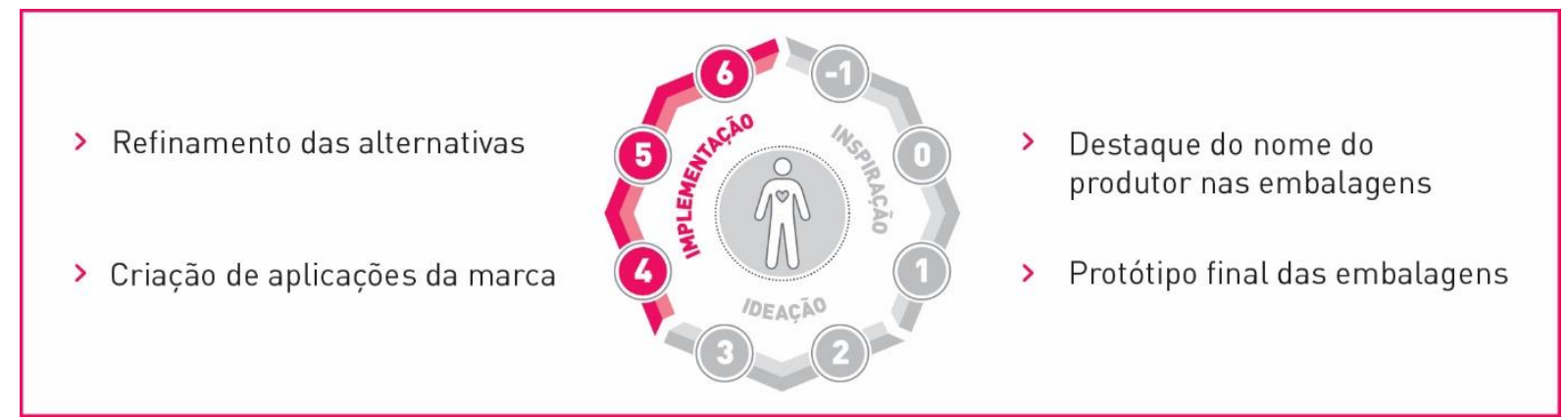

Ilustração 7 - Resumo do Momento Ideação do GODP

Fonte: Os Autores, 2018.

$\mathrm{Na}$ etapa 4 as alternativas foram refinadas, os protótipos das embalagens foram desenvolvidos e a identidade visual foi aplicada em materiais de papelaria, uniforme, redes sociais, entre outros. $\mathrm{Na}$ Identidade Visual buscou-se utilizar com maior recorrência as cores laranja e bordô, já presentes na marca; por este motivo, essas cores ganharam maior destaque nas aplicações. Foi feita a aplicação da marca em uniformes (a), aventais (b) e ecobags (c). Foram desenvolvidos materiais de papelaria (d), como cartões de visita, papel timbrado e envelope, pois os produtores participam de feiras e eventos para promover seus produtos. Além disso, a ecobag com o logo da AJAAR pode ser utilizada pelos consumidores como alternativa à sacola plástica e ainda ajuda a divulgar a marca. Também foi proposta a plotagem em veículos (e), página de empresa no Facebook (fanpage) para divulgação na internet e informar sobre datas de feiras e eventos. Foram ainda projetadas placas de sinalização para serem utilizadas na frente do empreendimento de cada produtor (f), placas para serem utilizadas em feiras e eventos (g) e uma placa para ser utilizada na estrada para mostrar o caminho (h). As aplicações desenvolvidas podem ser visualizadas na ilustração a seguir.

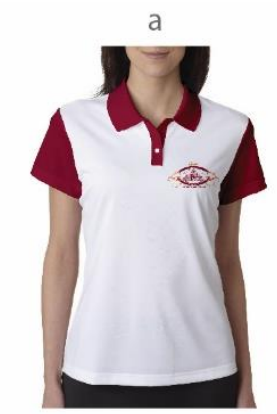

e
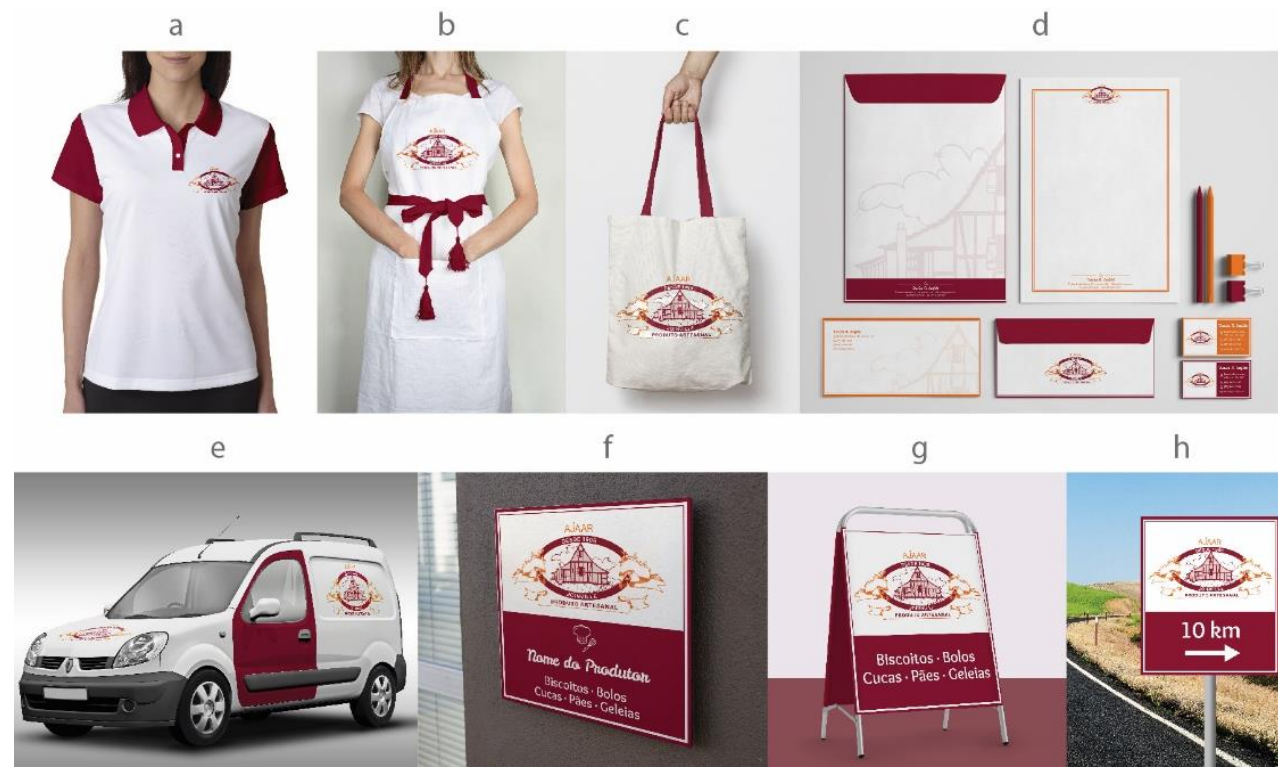

g

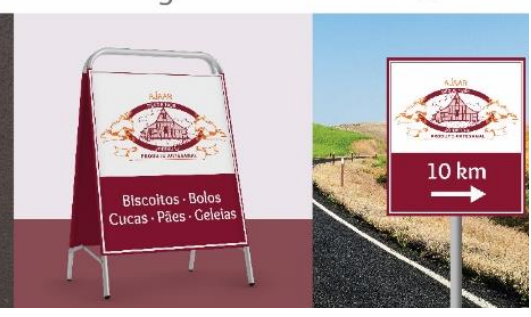

Ilustração 8 - Aplicações da Marca Fonte: Os Autores, 2018. 
Um Sistema de Identidade Visual para a identificação e diferenciação de produtos da agricultura familiar

Além da elaboração de materiais de papelaria, uniforme e sinalização, esta ação teve como objetivo o desenvolvimento de embalagens para acondicionar os panificados - sem que estes fossem danificados ou quebrassem no transporte -, e a criação de tags e selos de identificação do produtor como forma de identificar e valorizar o produtor individualmente dentro da associação.

\section{Identificação do Produtor}

Foram desenvolvidas duas alternativas de tags nas cores da identidade visual da AJAAR, uma no formato redondo e outro pentagonal. Elas serão fixadas nas embalagens com fitas de cetim na mesma cor das tags. $\mathrm{Na}$ face frontal pode ser visto o nome do produtor, endereço e telefone, no verso um pictograma representa o produtor, e abaixo traz uma breve descrição sobre ele (ilustração 9). A escolha entre os formatos das tags e do selo pode depender do tamanho e formato da embalagem, assim como da preferência pessoal e das necessidades do produtor

Foi desenvolvido também o selo de identificação do produtor para ser utilizado nas circunstâncias onde não for possível amarrar as tags, como em caixas, por exemplo. Foram feitos dois tamanhos para serem usados, dependendo do tamanho da embalagem. No selo maior consta o nome e uma breve descrição sobre o produtor e seus produtos, endereço e telefone. O selo menor informa o nome do produtor, endereço e telefone. As tags e os selos de identificação do produtor podem ser vistos na ilustração 9 .

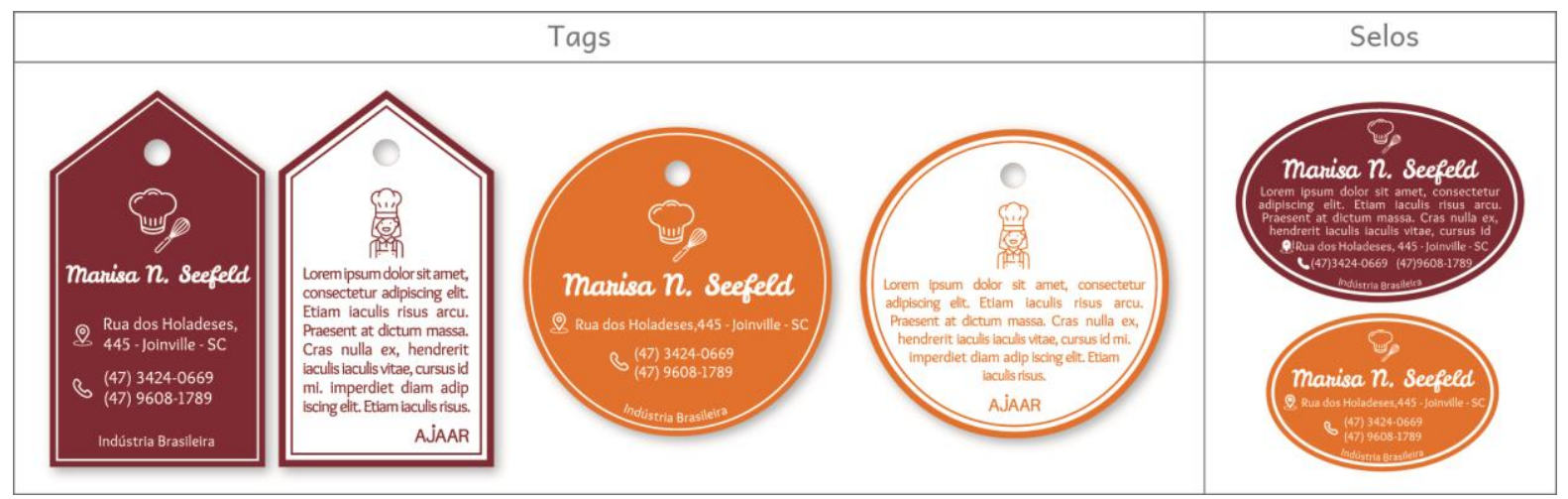

Ilustração 9 - Identificação do Produtor Fonte: Os Autores, 2018.

\section{Embalagens}

As embalagens desenvolvidas consideraram a grande quantidade de produtores de panificados existentes na associação. Por este motivo, várias alternativas foram elaboradas para as embalagens de pães, bolos, cucas e biscoitos, considerando a variedade de produtos e sabores. As preferências e necessidades pessoais de cada produtor foram consideradas, de forma a facilitar e tornar o processo de embalar personalizável, porém de forma a manter a unidade e refletir a identidade visual da associação. 
Um Sistema de Identidade Visual para a identificação e diferenciação de produtos da agricultura familiar

Para a embalagem de pão (ilustração 10) foi desenvolvido um rótulo adesivo menor para a frente - de modo que o produto pudesse ser melhor visualizado, sendo também que a embalagem é transparente; e um outro rótulo para o verso no qual podem ser lidas as demais informações. No rótulo constam as informações obrigatórias que devem estar incluídas no painel principal, segundo a norma RDC no 259 da ANVISA (BRASIL, 2002), são elas: a marca, a denominação de venda do alimento e a quantidade nominal do conteúdo do produto. No verso há um espaço com um pequeno texto sobre a associação e sua história, a fim de informar ao consumidor sobre a associação, bem como demais informações obrigatórias por lei.

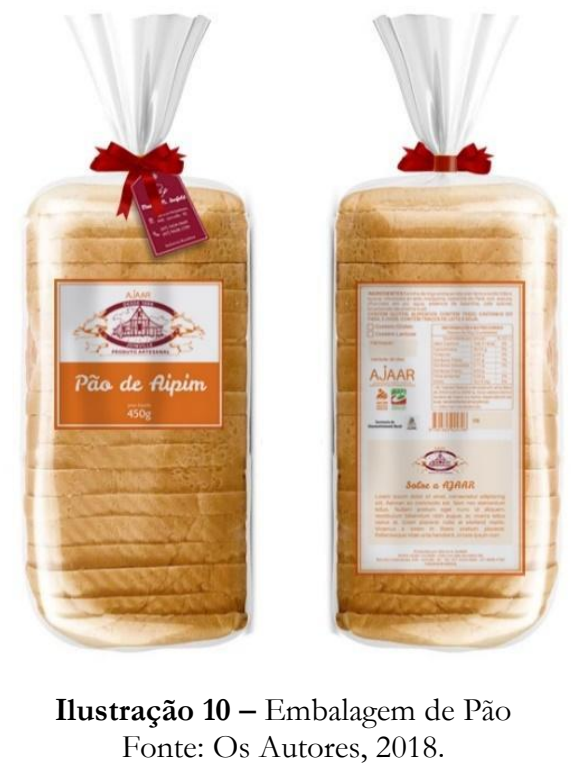

Foram desenvolvidas 3 alternativas para as embalagens de bolos e cucas que podem ser utilizadas a critério do produtor dependendo das suas necessidades e do produto oferecido, conforme ilustração 11. A alternativa 1 é um rótulo adesivo para a frente e outro para o verso, que pode ser utilizado em embalagens plásticas - sendo que o da frente é menor de forma a facilitar na visualização do produto. A alternativa 2 é uma caixa de papelão, com uma janela para a visualização do produto na tampa, envolta com uma cinta de papel que contém as informações do rótulo. $\mathrm{Na}$ alternativa 3 foi utilizada a mesma caixa da alternativa anterior, porém no lugar da cinta serão utilizados rótulos adesivos. Nas laterais mais estreitas da caixa serão colados os rótulos com as demais informações.

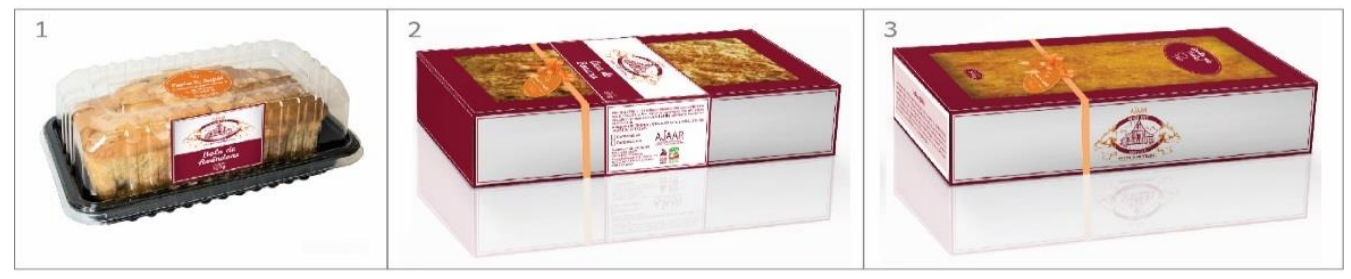

Ilustração 11 - Embalagens de Bolos e Cucas Fonte: Os Autores, 2018. 
Um Sistema de Identidade Visual para a identificação e diferenciação de produtos da agricultura familiar

Para os biscoitos, foram desenvolvidas 7 alternativas (ilustração 12). A primeira é um rótulo adesivo para embalagem plástica, que já era utilizado pela associação, porém com um novo layout e aplicação na frente e no verso da embalagem. Para a alternativa 2, foi desenvolvido uma cinta para as embalagens de isopor, que eram utilizadas anteriormente pela associação para armazenar bolachas decoradas; a cinta envolverá a bandeja de isopor, deixando um espaço para a visualização do produto. A alternativa 3 também será usada no pacote de biscoitos, onde o rótulo será grampeado na parte superior do pacote, deixando o restante da embalagem transparente a fim de mostrar o produto. A quarta alternativa para os biscoitos possui uma cinta que envolve o pacote de biscoitos verticalmente e é grampeado na parte superior; desta forma, o rótulo protege os biscoitos da quebra; nas laterais é possível visualizar o produto. A alternativa 5 é uma caixa que envolve os biscoitos como um todo, protegendo-os da quebra; os biscoitos ficam inseridos dentro de um saco plástico para manter sua crocância e a caixa possui um visor frontal, e selo de identificação do produtor fixado na tampa. A embalagem da alternativa 6 é composta por uma caixa com um visor retangular na tampa e envolta por uma cinta com as informações do rótulo. Por ser um visor maior que o da alternativa anterior e acondicionar bem o produto, impede a quebra, contribui para a visualização das bolachas decoradas. A alternativa 7 utiliza a mesma embalagem da alternativa anterior, porém no lugar da cinta serão utilizados rótulos adesivos nas laterais mais estreitas da caixa.

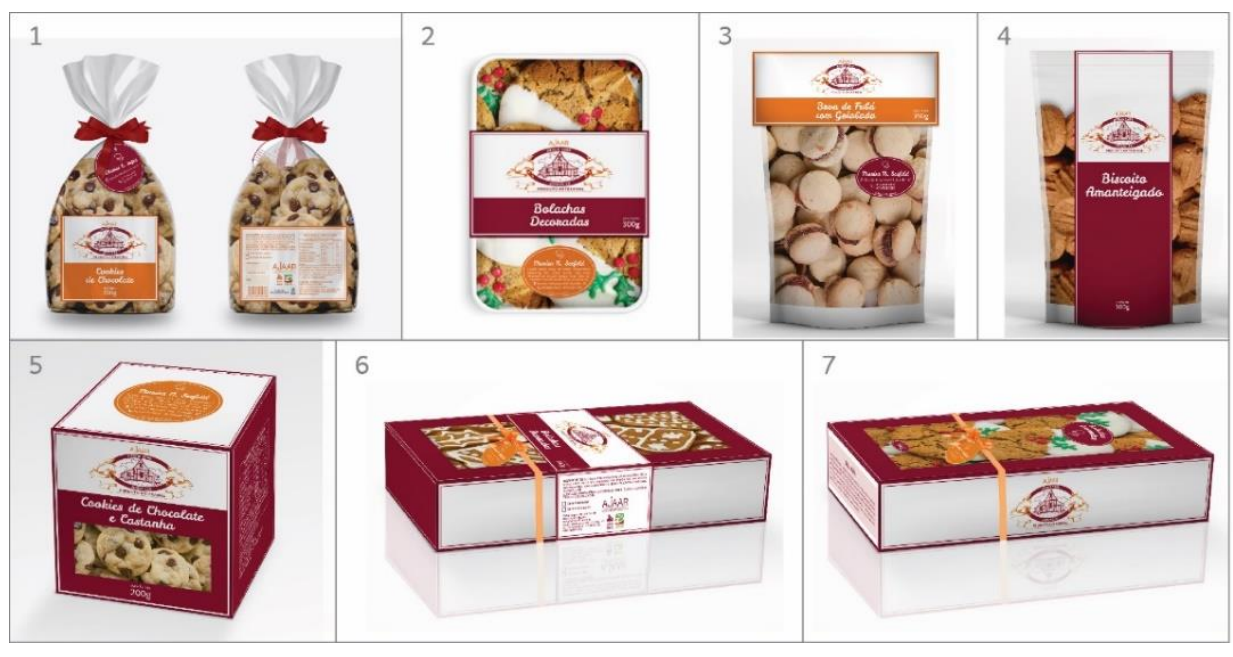

Ilustração 12 - Embalagens de Biscoitos Fonte: Os Autores, 2018.

As fragilidades identificadas inicialmente, como a falta de identificação visual dos produtores e a presença de embalagens inadequadas, foram solucionadas com a criação das tags e selos de identificação do produtor e o desenvolvimento de embalagens que acondicionam os produtos adequadamente, de forma a evitar a quebra durante o transporte, e manter a unidade visual do empreendimento. 
Um Sistema de Identidade Visual para a identificação e diferenciação de produtos da agricultura familiar

$\mathrm{Na}$ etapa 5 foram feitas as verificações finais e a viabilização do projeto, na qual é testado em situação real. Atualmente o projeto encontra-se em andamento e está sendo implementado. Algumas aplicações, como uniformes (blusas polo e aventais) e cartões de visita, já foram implementadas e estão sendo utilizadas pelos membros da AJAAR.

\section{CONCLUSÃO}

Esta ação surgiu a partir da oportunidade de desenvolver um Sistema de Identidade Visual e embalagem para o segmento de panificados - pães, bolos, cucas e biscoitos - da AJAAR, pois foi identificada fragilidade nas suas embalagens que não protegiam corretamente o produto e os danificavam durante o transporte e a exposição. Além disso, a associação necessitava de ajustes em sua identidade visual (marca), de modo a torna-la mais legível e organizada, com o objetivo de gerar maior unidade e consequentemente maior reconhecimento e diferenciação.

Durante a ação de extensão, percebeu-se também a necessidade de destacar os produtores de forma individual; para isso foram criadas tags de identificação com informações sobre o produtor que são fixadas nas embalagens.

Para o desenvolvimento desta ação foi utilizada a metodologia GODP, que a partir das suas ferramentas de análise - pensando no produto, usuário e contexto -, e com seu desenvolvimento centrado no usuário, permitiu com que o sistema de embalagem desenvolvido fosse consistente com os requisitos propostos, assimilado e aceito pela associação, tendo em vista se tratar de um processo flexível, que foca na participação de todos os envolvidos.

O desenvolvimento de um sistema de identidade visual e suas aplicações, com destaque para as embalagens de panificados, de modo a valorizar as características diferenciadoras do empreendimento, refletidas nos conceitos projetuais foi a principal contribuição desta ação. Obteve-se maior consistência por meio do ajuste na marca gráfica, bem como unidade na comunicação do empreendimento por meio da definição de padrões de forma e cor.

Os produtos da AJAAR já eram reconhecidos na região por sua qualidade. Deste modo, o design veio como contribuinte para comunicar visualmente essa qualidade ao consumidor, diferenciando e valorizando. Destaca-se também o foco dado ao produtor, considerando suas necessidades desde a montagem personalizável das embalagens até a sua identificação no ponto de venda, proporcionando uma maior visibilidade e destaque entre seus concorrentes.

O desenvolvimento desta ação de extensão trouxe a oportunidade de realizar um contato direto com os produtores, onde foi possível aferir como o design pode contribuir na valorização de produtos da agricultura familiar, apoiando os produtores de Santa Catarina, favorecendo sua 
Um Sistema de Identidade Visual para a identificação e diferenciação de produtos da agricultura familiar

participação no mercado, impulsionando a economia e incentivando o consumo de produtos locais. Além disso, beneficiou os associados da AJAAR e suas famílias auxiliando na melhoria da autoestima em relação a seus produtos e motivando sua produção, configurando um projeto participativo que aproxima a UFSC com a sociedade. Como futuras ações estão previstas a implementação das embalagens e demais aplicações desenvolvidas.

\section{AGRADECIMENTOS}

Agradecimentos à AJAAR, junto a EPAGRI - Empresa de Pesquisa Agropecuária e Extensão Rural de Santa Catarina, Governo de Santa Catarina e SC Rural, Banco Mundial, Próreitora de Extensão da UFSC, Fundação de Amparo à Pesquisa e Extensão Universitária (FAPEU) e demais agências de fomento.

\section{REFERÊNCIAS}

ABRE, Associação Brasileira de Embalagem. Embalagem. Disponível em: http://www.abre.org.br/setor/apresentacao-do-setor/a-embalagem/. Acesso em: 01 mar. 2018.

AGÊNCIA NACIONAL DE VIGILÂNCIA SANITÁRIA (Brasil). Resolução RDC no 259, de 20 de setembro de 2002. Aprova o Regulamento técnico para rotulagem de alimentos embalados. Diário Oficial [da] República Federativa do Brasil, Brasília, DF, 23 set. 2002.

ALTMANN, R.; MIOR, L.C.; ZOLDAN, P. Perspectivas para o sistema agroalimentar e o espaço rural de Santa Catarina em 2015: Percepção de representantes de agroindústrias, cooperativas e organizações sociais. Florianópolis: Epagri, 2008.

BAXTER, Mike. Projeto de Produto. São Paulo: Edgard Blücher, 2000.

BRASIL. Resolução RDC no 259, de 20 de setembro de 2002. Aprova o Regulamento Técnico sobre Rotulagem de Alimentos Embalados. Diário Oficial [da] República Federativa do Brasil, Brasília, 23 set. 2002. Disponível em: http://portal.anvisa.gov.br/documents/10181/2718376/

RDC_259_2002_COMP.pdf/9c816a4d-2dc7-48bf-80e4-e8891f640cf2. Acesso em: 21 out. 2017.

CORREIA, Margarita; DE LEMOS, Lúcia San Payo. Inovação lexical em português. Colibri, 2005.

GIL, Antônio Carlos. Como elaborar projetos de pesquisa. São Paulo: Atlas, 2002.

IBGE. Instituto Brasileiro de Geografia e Estatística. Disponível em: http://www.ibge.gov.br/home/estatistica/economia/agropecuaria/censoagro/ .Acesso em 28 de Fev. de 2018

MDA, Ministério do Desenvolvimento Agrário. O que é Agricultura Familiar? 2016. Disponível em: http://www.mda.gov.br/sitemda/noticias/o-que-é-agricultura-familiar. Acesso em: 28 Fev. 2018. 
Um Sistema de Identidade Visual para a identificação e diferenciação de produtos da agricultura familiar

MERINO, Giselle Schmidt Alves Díaz. GODP - Guia de Orientação para Desenvolvimento de Projetos: Uma metodologia de Design Centrado no Usuário. Florianópolis: Ngd/ Ufsc, 2016. Disponível em: www.ngd.ufsc.br. Acesso em: 20 abr. 2017.

Merino, Giselle S. A. D. et al. "DESIGN E AGRICULTURA FAMILIAR: AÇÕES DE VALORIZAÇÃO E IDENTIFICAÇÃO EM SANTA CATARINA", p. 1659-1670. In: Anais do $12^{\circ}$ Congresso Brasileiro de Pesquisa e Desenvolvimento em Design, Blücher Design Proceedings, v. 9, n. 2. São Paulo: Blücher, 2016.

PÉON, Maria Luísa. Sistemas de Identidade Visual. Rio de Janeiro: 2AB Editora ltda, 2000.

SEBRAE. Série Empreendimentos Coletivos: cooperar para competir. 2014. Disponível em: http://www.sebrae.com.br/sites/PortalSebrae/artigos/serie-empreendimentos-coletivos-cooperarpara-competir,2fa5438af1c92410VgnVCM100000b272010aRCRD. Acesso em: 01 mar. 2018

WHEELER, Alina. Design de identidade da marca: Guia Essencial para Toda a Equipe de Gestão de Marcas. Bookman Editora, 2012.

Recebido em: 26/05/2018

Aceito em: 26/03/2019 